\title{
Numerical Simulation of Biomass Gas Purification of Square Section Venturi Scrubber

\author{
Zhenhui Luan ${ }^{\mathrm{a}}$, Libo Zhu
}

(School of Mechanical Engineering, Anhui University of Science and Technology, Huainan 232001, China)

azhluan@aust.edu.cn, blibobo22222@tom.com

Keyword: venturi scrubber, square section, biomass gas, tar, efficiency

\begin{abstract}
Venturi scrubber is usually used to purify biomass gas. In order to improve efficiency of biomass gas purification of venturi scrubber, a test apparatus of the square section venturi scrubber was established to purify biomass gas. On the basis of analysis of the surge flow and the model selection of the standard $k-\varepsilon$ model, and suing CFD software, the inner flow field of biomass gas purification of the square section venturi scrubber was simulated, the internal pressure features and the speed features of the square section venturi scrubber were obtained. Compared to circular section venturi scrubber, the square section venturi scrubber has big turbulence intensity in the throat, and there will be flow back at the end of the pipe, which makes the tar particles inside the biomass gas better adsorption, so as to achieve better effect of decoking.
\end{abstract}

\section{Introduction}

Biomass gasification technology is to convert the agricultural waste by high temperature solid biomass pyrolysis gasification into high grade of combustible gas, which alternates to traditional fossil fuels, and as the application of the energy in our life, and can satisfy the urban and rural areas and rural areas energy used in cooking. The biomass gas can effectively relieve the energy in the form of tight supply, relieve the energy crisis in a certain extent, and is so popular with the attention of scholars both at home and abroad. The current application of biomass gasification on the broader is for fixed bed gasifier, however, after high temperature thermal chemical conversion, there will be inevitably by-product tar and other impurities in the biomass gas. Tar has a larger viscosity, and for a long time, it will jam the pipeline or kitchen. In order to purify biomass gas, people has used various means to reduce the harm of $\operatorname{tar}[1-2]$. Efficiency of biomass gas purification is very important to venturi scrubber, which determines venturi scrubber whether can be used in biomass gasification technology[3]. In order to improve efficiency of biomass gas purification of venturi scrubber, this paper established a test apparatus of the square section venturi scrubber, simulated the flow field and obtained some pressure features and the speed features of the venturi scrubber.

\section{Numerical Calculation}

The mathematical model: After studying all kinds of models, this paper selected the standard $\mathrm{k}-\varepsilon$ model, which is a double-equation model shown in Eq.1 and Eq.2 with introducing a turbulent dissipation rate $\varepsilon$ on the basis of the turbulent kinetic energy k equation[4].

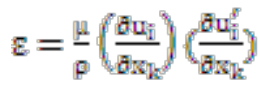

$$
\begin{aligned}
& \mu=\rho C_{\mu} \frac{k^{2}}{g}
\end{aligned}
$$

where $\mathrm{k}$ is the turbulent kinetic energy, $\varepsilon$ is the turbulent dissipation rate, $\mu$ is the eddy viscosity, $\mathrm{u}_{\mathrm{i}}$ is average velocity, $\mathrm{u}_{\mathrm{i}}^{z}$ is pulse velocity, $\mathrm{p}$ is density of the fluid, and $\mathrm{C}_{\mu}=0.0845$.

The transport equations of the standard $k-\varepsilon$ model can be deduced from the above two 
equations, which are shown in Eq.3 and Eq.4.

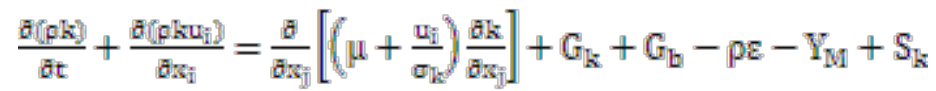

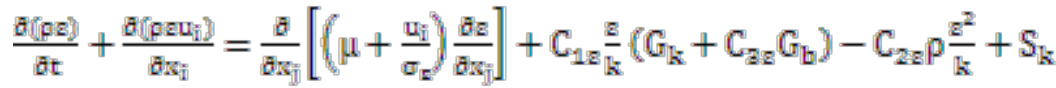

where $G_{k}$ is turbulence kinetic energy caused by the average velocity gradien, which is shown in Eq.5.

$$
\mathrm{G}_{\mathrm{k}}=\mathrm{u}_{\mathrm{i}}\left(\frac{\partial \mathrm{u}_{\mathrm{i}}}{\partial \mathrm{x}_{\mathrm{j}}}+\frac{\partial \mathrm{u}_{\mathrm{i}}}{\partial \mathrm{w}_{\mathrm{i}}}\right) \frac{\partial \mathrm{u}_{\mathrm{i}}}{\partial \mathrm{u}_{\mathrm{i}}}
$$

and $\mathrm{G}_{\mathrm{b}}$ is turbulence kinetic energy caused by the buoyancy, which is shown in Eq.6.

$$
\mathrm{G}_{\mathrm{b}}=\beta \mathrm{g}_{\mathrm{i}} \frac{\mathrm{W}_{\mathrm{i}}}{\mathrm{Prf}_{\mathrm{rf}}} \frac{\partial \mathrm{T}}{\partial \mathrm{W}_{\mathrm{i}}}
$$

and $\mathrm{Y}_{\mathrm{M}}$ is turbulence kinetic energy caused by the compressible fluid, which is shown in Eq.7.

$$
\mathrm{Y}_{\mathrm{M}}=2 \mathrm{peM} \mathrm{i}_{\mathrm{i}}^{2}
$$

and $\beta$ is thermal expansion coefficient, $\mathrm{M}_{\mathrm{i}}$ is turbulent Mach number, $\mathrm{C}_{1 \varepsilon}, \mathrm{C}_{2 \varepsilon}$ and $\mathrm{C}_{a \varepsilon}$ are constants determined by experience, $\mathrm{C}_{18}=1.44, \mathrm{C}_{2 \varepsilon}=1.92, \mathrm{C}_{a z}=0.99$, and $\sigma_{\mathrm{k}}=1.0, \sigma_{\varepsilon}=1.3$, $\mathrm{p}_{\mathrm{rf}}=0.85$.

\section{Before Processing of Numerical Simulation}

Venturi scrubber is mainly composed of three parts of converging section, throat and diverging section. In the converging section, washing liquid is sprayed by the nozzle into the biomass gas stream, and the nozzle is installated in the center of the converging section[5-6]. The collision between washing liquid droplets with tar can congeal tar particles which can be adsorbed by the droplets, and the droplets adsorbed tar sink down and the biomass gas is cleansed. Table 1 is the structure parameters of square cross section venturi scrubber, and Fig. 1 for structure.

This paper build the model of the square section venturi sccrubber with 3D modeling software, and choosed unstructured grid, which can guarantee calculation accuracy and convergence speed, and the grid precision can reach 0.38. The model of the tube is shown in Fig.2.

Table 1 The structure parameters of square section venturi scrubber

\begin{tabular}{lcccccc}
\hline parameter & $\mathrm{D}_{1}$ & $\mathrm{D}_{0}$ & $\mathrm{D}_{2}$ & $\mathrm{a}_{1}$ & $\mathrm{a}_{2}$ & $\mathrm{~L}_{0}$ \\
& $/ \mathrm{mm}$ & $/ \mathrm{mm}$ & $/^{\circ}$ & $/^{\circ}$ & \\
\hline numeric & 100 & 50 & 100 & 22 & 6 & 100 \\
\hline
\end{tabular}

\section{Numerical simulation of internal flow field}

Set boundary conditions: This paper set velocity inlet as the entry of the venturi scrubber, and the inlet velocity was set to $10 \mathrm{~m} / \mathrm{s}$. We set free flow as the outlet of the tube, and no slip for wall conditions. We set the biomass gas as continuous phase, and tar and washing liquid droplet as dispersed phase. We set the wall thickness of the venturi scrubber as $3 \mathrm{~mm}$, and material as Q235 steel. We set the inlet temperature of the gas of the venturi scrubber as $50^{\circ} \mathrm{C}$ and the outlet temperature of the gas as $30^{\circ} \mathrm{C}$, as the venturi scrubber has the effect of the cooling fluid in pipe, inculding the effect of heat exchange, heat conduction, heat radiation and heat convection between the fluid and the wall and the the environment. 


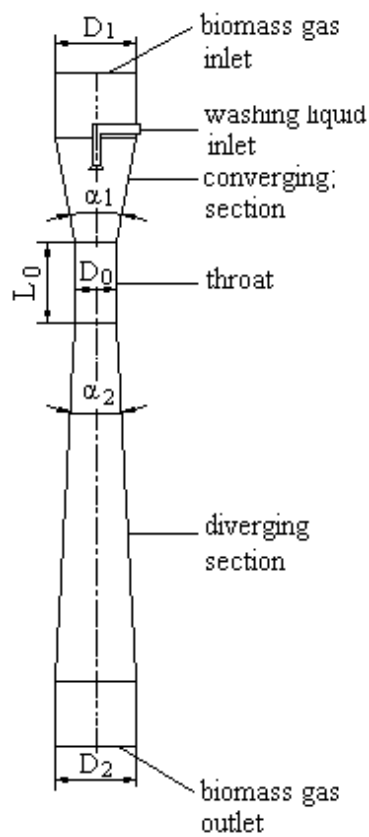

Fig.1 Structure of the square venturi tube

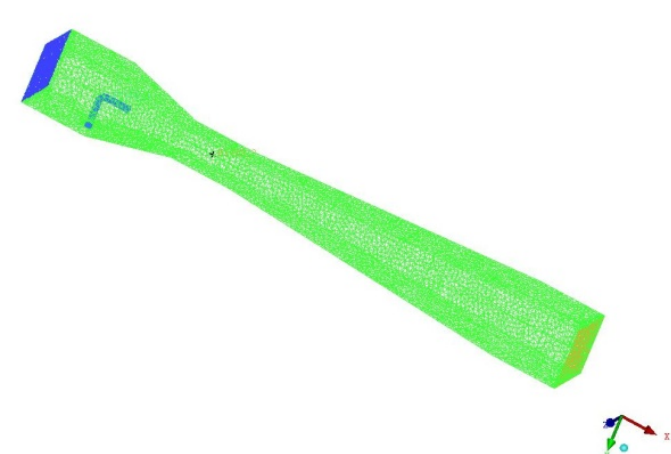

Fig.2 Meshing diagram of the square venturi tube

Select the model: According to [7], the flow of the venturi scrubber is turbulent, so we choosed the standard $\mathrm{k}-\varepsilon$ turbulence model, and choosed the Simple algorithm to iterate, set up the residuals of convergence to iterate.

When the continuous phase achieved convergence, we joined the discrete phase DPM, and set an injection for washing liquid discrete phase, selected the atomization model pressure-swirl-atomizer, set an injection for tar, choosed the surface type and added the discrete phase surface as gas entrance. We set the wall effect of particles, selected trap type as the inner wall of the venturi scrubber, and selected escape type as the venturi scrubber gas exports, and then iterated until convergence.

\section{Analysis and Comparison of the Simulation Results}

The velocity characteristics: The velocity characteristics of multiphase flow in venturi scrubber plays a decisive role in the purification process of biomass gas. Fig. 3 is the speed contours of the square section venturi scrubber, and Fig.4 is that of circular section one.

In Fig.3 and Fig.4, the velocity of the fluid in venturi scrubber has a gradient variation characteristics because of the converging section. As the pipe diameter reduces the speed of the fluid increases rapidly, and it reachs maximum velocity when it is in throat. After throat the velocity reduces as the pipe diameter increases. It can be seen from the two diagrams that the velocity change uniformity in the square section is poorer than that in circular section one, but the maximum velocity in throat of the square section is greater than that of circular section one. There is a tail backflow at the end of the square tube, and this has a strengthening effect for decoking.

The pressure characteristics: The pressure characteristics of the flow in venturi scrubber reflects the pressure loss and the decoking efficiency of venturi tube, which has a gradient variation characteristics. At the entrance of venturi scrubber the pressure is the maximum, and then the pressure has been negative. There is a sharp decline at first, then the pressure reduces to the minimum in throat, and then has a slow recovery after throat. The fluid has a turbulence in converging section due to washing liquid tube, and here is a whirlpool. At the same time, because of the discrete phase injection of the washing liquid droplets the pressure has a certain fluctuations. Fig. 5 is the pressure contours of the square section venturi scrubber, and Fig. 6 is that of circular section one. 


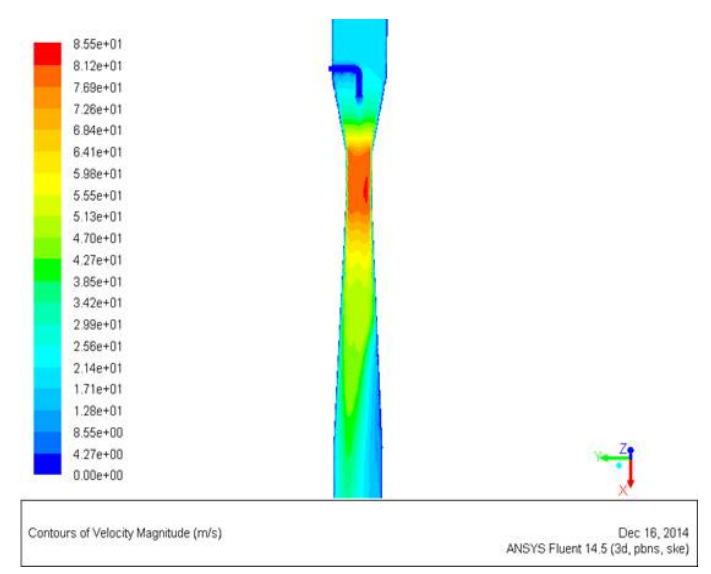

Fig.3 Velocity contours of the square venturi tube

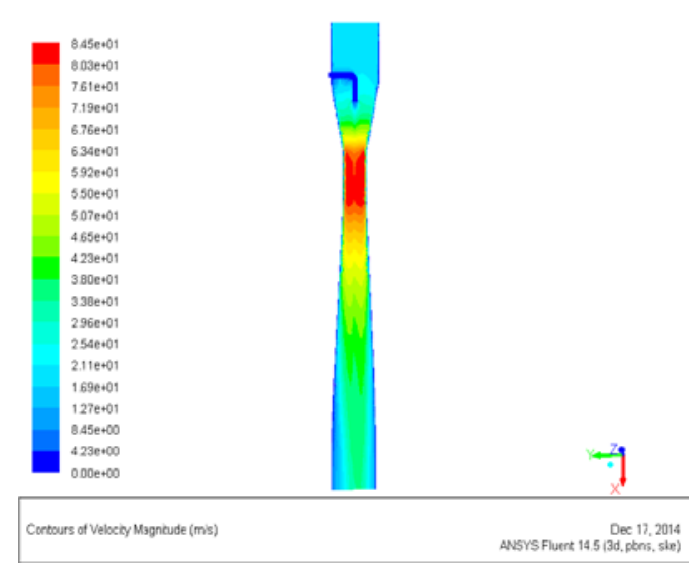

Fig.4 Velocity contours of circular venturi tube

From Fig. 5 and Fig.6, it can be seen that there is a uniform pressure change in circular section venturi scrubber, and there is not a uniform pressure change in the square section venturi tube. In throat of the square section venturi scrubber, the pressure can achieve lower negative pressure value, therefore the square section venturi scrubber has also a strengthening effect for decoking.

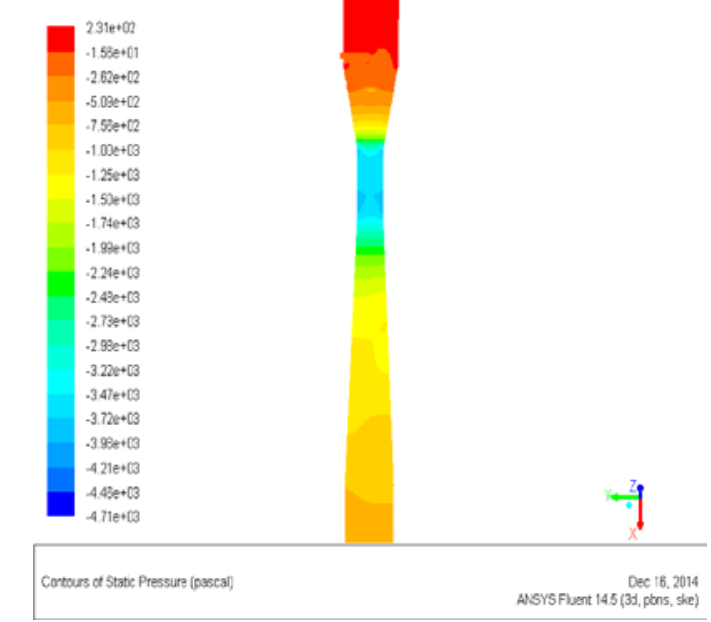

Fig.5 Pressure contours of the square venturi tube

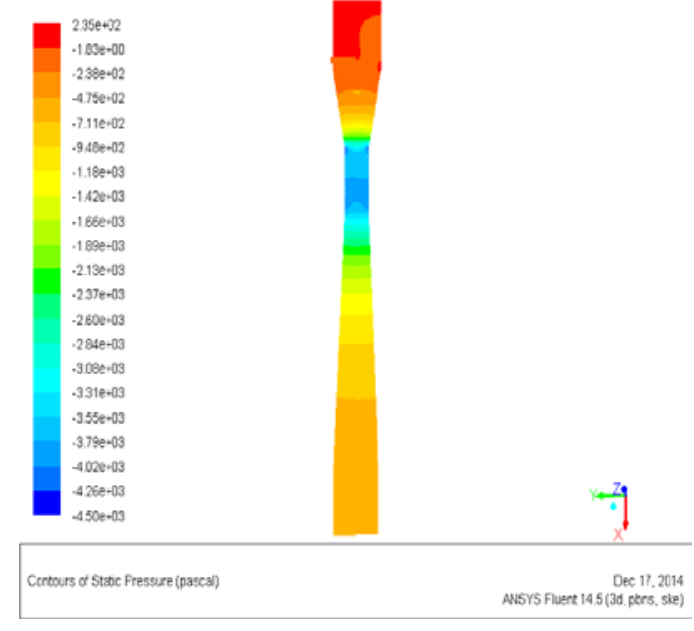

Fig.6 Pressure contours of circular venturi tube

\section{Conclusion}

The decoking purification efficiency of venturi scrubber depends on the pressure loss of the internal flow field. The greater the pressure loss is in the flow field, the more obvious the decoking effect is of the venturi scrubber. The pressure loss includes wall friction loss and fluid flow loss. The flow uniformity of the square section venturi scrubber is poorer than that of circular section one and the wall friction of the square section venturi scrubber is also bigger, and there is a tail backflow at the end of the square section venturi scrubber, so the pressure loss of the square section venturi scrubber is bigger than that of circular section one, and the decoking purification efficiency of the square section venturi scrubber is higher than that of circular section one.

\section{Reference}

[1] Wang wulin. Biomass gasification technology and tar purification method. Journal of Agricultural Mechanization Research. 2010(4):182-184(In Chinese).

[2] Chen Lianguo, Chen Zhili, Yu Jingchun, et al. Application Status of Biomass Carbonization and Pyrolysis Technologies. Gas and Heat, 2013,33(11):32-34(In Chinese).

[3] Wang Yan, Chen Wenyi, Sun Jiao, et al. Research progress in biomass gasification equipment. Chemical Industry and Engineering Progress. 2012,31(8):1656-1664(In Chinese).

[4] Chang jiafu. Research on the Characteristics of Venturi Scrubber Purifying Biomass Gas. 
Shandong University, 2013.5(In Chinese).

[5] Zhang Changqing, Ding Decheng. Process Calculation for Venturi Scrubber. SP \& BMH RELATED ENGINEERING, 2011(6):6-10(In Chinese).

[6] Dang yuchun, Liu hongbin, Ding qingguo. Effects of geometric parameters on venture scrubber purifying biomass gas. Journal of Chinese Agricultural Mechanization, 2014,35(2):115-118(In Chinese).

[7] Chang jiafu, Dong yuping, Liu qinglei, et al. Experimental study and numerical simulation on flow field of venturi scrubber purifying biomass gas. Transactions of the Chinese Society of Agricultural Engineering, 2012,28(21):186-192(In Chinese). 